\title{
PENGARUH INDUSTRI SEDANG DAN BESAR TERHADAP TINGKAT KEMISKINAN DI KABUPATEN GRESIK TAHUN 2002-2016
}

\section{Rohmatul Janah, Ida Nuraini}

Program Studi Ekonomi Pembangunan, Fakultas Eknomi dan Bisnis, Universitas Muhammadiyah Malang, Jl.Raya Tlogomas No.246 Malang, Indonesia

* Corresponding author : rohmatuljannah74@gmail.com

\begin{tabular}{|c|c|}
\hline Artikel Info & Abstract \\
\hline Article history: & This research is aimed at studying the influence of medium \\
\hline Received 6 August 2019 & and large indutries on poverty levels in Gresik on 2002-2016. \\
\hline Revised 7 September 2019 & The variables used in this study is medium and large industris, \\
\hline Accepted 20 December 2019 & labor of medium and large industries, gross regional domestic \\
\hline Available online 15 February & product $(G R D P)$ of industrial sector and poverty rate. The \\
\hline 2020 & $\begin{array}{l}\text { method used in this study used multiple linear regression and } \\
\text { used time series data. The results of this study simultaneously }\end{array}$ \\
\hline $\begin{array}{l}\text { Keyword: Medium and large } \\
\text { industries; labor; poverty. }\end{array}$ & $\begin{array}{l}\text { are the variables of the amount of medium and large industries, } \\
\text { the labor medium and large industries, and the gross regional } \\
\text { domestic produk (GRDP) of industrial sector to poverty rate is }\end{array}$ \\
\hline JEL Classification & significant. While medium and large industries to poverty rate \\
\hline $\mathrm{E} 32, \mathrm{O} 14$ & $\begin{array}{l}\text { has negative and insignigicant effect with a coefficient value of } \\
-0,208905 \text {. The labor of medium and large industries to } \\
\text { poverty rate has positive and significant effect with a coefficient } \\
\text { value of } 0,130822 \text {, the gross regional domestic product } \\
\text { (GRDP) of industrial to poverty rate has a negative and } \\
\text { significant effect with a coefficient value of -0,169431 }\end{array}$ \\
\hline
\end{tabular}

\section{PENDAHULUAN}

Negara-negara sedang berkembang di dunia termasuk Indonesia dihadapkan pada suatu permasalahan yaitu kemiskinan (Mahsunah, n.d.). Kemiskinan timbul akibat perbedaan kemampuan, perbedaan kesempatan, dan perbedaan sumberdaya (Maipita, 2014). Berbagai macam perspektif yang tersedia dalam menelaah kemiskinan, seperti dari sisi agama sosial, budaya, ekonomi, politik ataupun psikologi dan lain-lain memungkinkan setiap orang untuk melakukan penafsiran berdasarkan "kepentingan" mereka (Suliswanto, Abdullah, \& Yuli, 2018).

Secara sederhana Kemiskinan dapat didefinisikan sebagai ketidakmampuan seseorang untuk memenuhi standar hidup yang minimum, yaitu suatu tingkat kekurangan materi pada sejumlah atau segolongan orang dibandingkan dengan standar kehidupan yang umum berlaku dalam masyarakat yang bersangkutan (Susilowati \& Suliswanto, 2015). Standar hidup yang rendah tersebut terwujud salah satunya dalam bentuk tingkat pendapatan yang sangat rendah atau kemiskinan (Todaro \& Smith, 2006).

Jumlah penduduk miskin di daerah pedesaan masih cukup banyak dibandingkan dengan daerah perkotaan (Murohman, Hutagaol, \& Asmara, 2014). Hal ini dikarenakan pengangguran tersembunyi masih cukup banyak di daerah pedesaan, mereka ini umumnya adalah buruh tani yang tidak memiliki lahan atau pengusaha tani dengan modal minim dimana akses ke lembaga keuangan formalpun sangat terbatas (Sudarti, 2011).

Kemiskinan merupakan salah satu tolak ukur kondisi sosial ekonomi dalam menilai keberhasilan pembangunan yang dilakukan pemerintah di suatu daerah (Susanti, 2013). Salah satu aspek yang peranan penting dalam 
penanggulangan kemiskinan tepat sasaran adalah tersedianya data kemiskinan yang akurat dan terpercaya untuk dipakai dalam menentukan nilai ukuran kemiskinan (Tambunan, 2003). Salah satu hal yang dapat dilakukan untuk pengurangan kemiskinan adalah perluasan lapangan pekerjaan yang dapat dilakukan dengan pembangunan pada sektor industri.

Sektor industri dipandang sebagai sektor yang memiliki tingkat produktifitas yang tinggi, sehingga dengan keunggulan sektor industri akan didapat nilai tambah yang tinggi yang pada akhirnya tujuan menciptakan kesejahteraan masyarakat secara ekonomi lebih cepat terwujud (Arifin, 2006). Selain itu Sektor industri dianggap sebagai the leading sector yang mampu mendorong berkembangnya sektor-sektor yang lain, seperti sektor jasa dan pertanian (Arsyad, 2010). Untuk itu setidaknya informasi mengenai beberapa faktor yang sangat membantu dalam pengembangan industri sangat diperlukan (Nuraini, 2013).

Penelitian (Tisniwati, 2012) bertujuan untuk mengetahui faktor-faktor yang mempengaruhi tinggi rendahnya kemiskinan di Indonesia. Penelitian ini menggunakan model regresi linier berganda. Hasil dari penelitian ini adalah variabel angka harapan hidup berpengaruh negatif dan signifikan terhadap kemiskinan di Indonesia.

Penelitian (Wahyuningsih \& Zamzami, 2014) bertujuan untuk mengetahui pengaruh pendapatan regional yang diproksi dengan PDRB riil dan jumlah penduduk berpengaruh terhadap tingkat kemiskinan di Kabupaten Nagan Raya. Penelitian ini menggunakan regresi berganda dalam bentuk logaritma. Hasil penelitian menunjukkan bahwa variabel produk domestik regional bruto berpengaruh negatif dan signifikan terhadap tingkat kemiskinan, variabel jumlah penduduk berpengaruh negatif dan signifikan terhadap tingkat kemiskinan.

Penelitian (Barirah, 2015) untuk mengetahui seberapa besar dan sejauh mana variabel-variabel seperti pertumbuhan ekonomi, jumlah tenaga kerja, dan inflasi berpengaruh pada kemiskinan di kota Surakarta tahun 1995-2013. Penelitian ini menggunakan regresi berganda. Hasil penelitian menunjukkan bahwa variabel produk domestic regional bruto (PDRB) berpengaruh negatif dan signifikan terhadap variabel kemiskinan, variabel jumlah tenaga kerja berpengaruh positif dan tidak signifikan terhadap kemiskinan dan variabel inflasi berpengaruh positif dan signifikan terhadap kemiskinan.

Penelitian (Heriansyah, Nuraini, \& Kusuma, 2018) untuk menganalisis kemiskinan serta menganalisis pengaruh variabel jumlah industri dan indeks pembangunan manusia terhadap jumlah penduduk miskin di kabupaten/kota Provinsi Banten. Penelitian ini menggunakan alat analisis regresi data panel. Hasil penelian menunjukkan bahwa variabel jumlah industri berpengaruh positif dan signifikan terhadap jumlah penduduk miskin. Sedangkan variabel indeks pembangunan manusia (IPM) berpengaruh negatif dan signifikan terhadap jumlah penduduk miskin.

Berdasarkan latar belakang diatas, permasalahan yang diangkat dalam penelitian ini adalah bagaimana pengaruh industri sedang dan besar terhadap tingkat kemiskinan di Kabupaten Gresik tahun 2002-2016.

\section{METODE PENELITIAN}


Lokasi yang diambil dalam penelitian ini adalah Kabupaten Gresik. Metode pengumpulan data yang digunakan dalam penelitian ini adalah metode dokumentasi, yaitu metode pengumpulan data yang berasal dari lembagalembaga terkait. Peneliti memperoleh data melalui Badan Pusat Statistika (BPS) Kabupaten Gresik dan Badan Pusat Statistika (BPS) Provinsi Jawa Timur.

Devinisi operasional variabel yang digunakan antara lain, tingkat kemiskinan yaitu penduduk yang tergolong tidak memiliki kemampuan untuk memenuhi kebutuhan standar hidup. Kemiskinan yang digunakan merupakan kemiskinan absolut berdasarkan data badan pusat statistika (BPS) Kabupaten Gresik. Jumlah industri sedang dan besar adalah industri yang mampu menyerap tenaga kerja dengan jumlah 20 sampai 99 orang pada sektor industri sedang dan sejumlah 100 orang atau lebih pada sektor industri. Tenaga kerja sektor industri sedang dan besar adalah penduduk yang berada pada rentang usia kerja dan melaksanakan pekerjaan di sektor industri sedang dan besar. PDRB sektor industri adalah jumlah nilai tambah barang dan jasa yang dihasilkan dari seluruh kegiatan pada sektor industri. Alat analisis yang digunakan dalam penelitian ini adalah regresi linier berganda. Regresi linier berganda digunakan untuk mengatahui pengaruh dua atau lebih variabel independen terhadap satu variabel dependen dalam penelitian dan dijelaskan dengan rumus sebagai berikut :

Penaksiran suatu model dikatakan baik apabila bersifat BLUE (Best Linear Unsbiased Estimator), yaitu bila memenuhi asumsi klasik atau terhindar dari masalah-masalah normalitas, multikolinearitas, heteroskedastisitas dan autokorelasi. Untuk itu dilakukan uji terhadap model untuk mengetahui apakah terjadi penyimpangan-penyimpangan terhadap asumsi klasik.

\section{HASIL DAN PEMBAHASAN}

Kabupaten Gresik secara umum dibagi menjadi dua wilayah yakni Gresik daratan dan Pulau Bawean dengan luas wilayah 1.191,25 kilometer persegi dan terdiri dari 18 kecamatan yang 2 kecamatan diantaranya berada di Pulau Bawean yakni Kecamatan Sangkapura dan Kecamatan Tambak, selain itu terdapat 330 desa dan 26 kelurahan. Kabupaten Gresik merupakan salah satu Kabupaten yang menyangga perekonomian di Provinsi Jawa Timur dan menjadi salah satu Kabupaten yang tergabung dalam kawasan Gerbangkertosusila (Gresik, Bangkalan, Mojokerto, Surabaya, Sidoarjo dan Lamongan).

Berdasarkan posisi geografis, Kabupaten Gresik berada pada lokasi yang sangat strategis bagi perekonomian nasional. Hal ini disebabkan karena posisi Kabupaten Gresik yang terletak pada selat Madura dan memiliki wilayah pesisir sepanjang $140 \mathrm{~km}$. selain itu sektor unggulan Kabupaten Gresik ada pada sektor industri, perdagangan dan jasa, pertanian, perikanan dan pariwisata. Sehingga diharapkan kawasan tersebut menjadi pusat -pusat pertumbuhan ekonomi bahkan dapat memacu pertumbuhan ekonomi daerahdaerah disekitarnya. 
Berikut dibawah ini merupakan rekapitulasi mengenai perkembangan tingkat kemiskinan, jumlah industri sedang dan besar, tenaga kerja industri sedang dan besar, serta produk domestic regional bruto (PDRB) sektor industri di Kabupaten Gresik dalam kurun waktu 2002-2016.

Tabel 1. Perkembangan Tingkat Kemiskinan, Jumlah Industri Sedang dan Besar, Tenaga Kerja Industri Sedang dan Besar serta Produk Domestik Regional Bruto Sektor Industri di Kabupaten Gresik Tahun 2012-2016

\begin{tabular}{ccccc}
\hline Tahun & $\begin{array}{c}\text { Tingkat } \\
\text { Kemiskinan }\end{array}$ & $\begin{array}{c}\text { Jumlah Industri } \\
\text { Sedang dan } \\
\text { Besar }\end{array}$ & $\begin{array}{c}\text { Tenaga Kerja } \\
\text { Industri Sedang } \\
\text { dan Besar }\end{array}$ & $\begin{array}{c}\text { PDRB } \\
\text { Sektor } \\
\text { Industri }\end{array}$ \\
\hline 2002 & - & - & - & - \\
2003 & 0,04 & 0,36 & $-0,20$ & 7,61 \\
2004 & 0,07 & 1,35 & 0,81 & 0,48 \\
2005 & $-0,16$ & $-0,84$ & 0,02 & 0,40 \\
2006 & 1,37 & $-0,50$ & $-1,38$ & 0,36 \\
2007 & $-0,39$ & 2,27 & 0,39 & 0,36 \\
2008 & $-0,76$ & 0,27 & 1,86 & 0,33 \\
2009 & $-0,78$ & $-0,95$ & 1,37 & 1,21 \\
2010 & $-1,24$ & 0,85 & $-0,25$ & 0,34 \\
2011 & $-0,53$ & $-0,07$ & $-11,80$ & 0,34 \\
2012 & $-0,37$ & 0,81 & 0,87 & 0,39 \\
2013 & $-0,14$ & $-3,88$ & 5,19 & 8,02 \\
2014 & $-0,19$ & 2,25 & 6,58 & 0,39 \\
2015 & 0,19 & 0,04 & $-0,26$ & 0,31 \\
2016 & $-0,18$ & $-1,99$ & $-1,88$ & 0,24 \\
\hline
\end{tabular}

Sumber : (BPS, 2016) data BPS diolah, 2019

Berdasar tabel 1, dapat diketahui perkembangan tingkat kemiskinan, jumlah industri sedang dan besar, tenaga kerja industri sedang dan besar serta produk domestik regional bruto (PDRB) sektor industri dalam kurun waktu 2002-2016 di Kabupaten Gresik. Tingkat kemiskinan dari tahun 2002-2016 mengalami kenaikan dan penurunan dibeberapa tahun (mengalami fluktuatif). Penurunan paling tinggi dalam kurun waktu 2002-2016 terjadi pada tahun 2006 yaitu sebesar $1,37 \%$. Sedangkan penurunan tingkat kemiskinan paling rendah terjadi pada tahun 2003, yaitu sebesar $0,04 \%$.

Jumlah industri sedang dan besar dari tahun 2002-2016 mengalami kenaikan dan penurunan di setiap tahunnya. Kenaikan jumlah industri tertinggi terjadi pada tahun 2007, yaitu sebesar 2,27\%. Sedangkan penurunan jumlah industri paling banyak terjadi pada tahun 2013 yaitu sebesar 3,88\%.

Tenaga kerja industri sedang dan besar dari tahun 2002-2016 mengalami kenaikan dan penurunan di setiap tahunnya. Kenaikan tenaga kerja industri sedang dan besar paling tinggi terjadi pada tahun 2014 yaitu sebesar 6,58\%. Sedangkan penurunan tenaga kerja industri sedang dan besar paling tinggi terjadi pada tahun 2011 yaitu sebesar 11,80\%. 
Produk domestic regional bruto (PDRB) sektor industri dalam kurun waktu 2002-2016 mengalami kenaikan setiap tahunnya. Kenaikan paling besar terjadi pada tahun 2013 sebesar 8,02\%. Sedangkan kenaikan yang paling kecil terjadi pada tahun 2016 yaitu sebesar 0,24\%.

Untuk mengetahui pengaruh variabel bebas secara simultan terhadap variabel terikat, maka digunakan uji $\mathrm{F}$. berdasarkan hasil uji $\mathrm{F}$ diperoleh hasil prob. f-statistic adalah signifikan, terlihat dari nilai f-statistic sebesar 9,462791 dengan nilai prob. f-statistic 0,002213 dan nilai ini lebih kecil dari 0,05. Sehingga disimpulkan bahwa variabel jumlah industri sedang dan besar, tenaga kerja industri sedang dan besar serta produk domestik regional bruto (PDRB) sektor industri secara simultan berpengaruh terhadap tingkat kemiskinan di Kabupaten Gresik. Sedangkan pada uji t diperoleh hasil dibawah ini:

\section{Tabel 2. Rekapitulasi Uji t}

\begin{tabular}{|c|c|c|c|c|}
\hline Variabel & Coefficient & Std, error & t statistic & Prob. \\
\hline $\begin{array}{c}\text { Jumlah Industri } \\
\text { Sedang dan Besar }\end{array}$ & $-0,208905$ & 0,464769 & $-0,449482$ & 0,6618 \\
\hline $\begin{array}{c}\text { Tenaga Kerja Industri } \\
\text { Sedang dan Besar }\end{array}$ & 0,130822 & 0,046120 & 2,836556 & 0,0162 \\
\hline PDRB Sektor Industri & $-0,169431$ & 0,037484 & $-4,520087$ & 0,0009 \\
\hline
\end{tabular}

Sumber: Eviews 9, diolah 2019

Berdasarkan tabel 2, variabel jumlah industri sedang dan besar berhubungan negatif dan tidak signifikan terhadap variabel tingkat kemiskinan, dengan nilai koefisien variabel jumlah industri sebesar $-0,208905$ dan probabilitas sebesar 0,6619 (lebih besar dari $\alpha=0,05$ ). Artinya, apabila terjadi kenaikan jumlah industri sebesar $1 \%$ maka kemiskinan akan menurun sebesar 20,89\% dengan asumsi bahwa variabel lain dianggap tetap. Meningkatnya jumlah industri tidak berpengaruh terhadap penurunan tingkat kemiskinan, dikarenakan pada industri sedang dan besar yang ada di Kabupaten Gresik merupakan industri padat modal. Bukan termasuk industri padat karya.

Variabel tenaga kerja industri sedang dan besar berhubungan positif dan signifikan terhadap variabel tingkat kemiskinan, dengan nilai koefisien tenaga kerja sektor industri sebesar 0,130822 dan probabilitas sebesar 0,0162 (lebih kecil dari $\alpha=0,05)$. Artinya, apabila terjadi kenaikan tenaga kerja sektor industri sebesar 1\% maka kemiskinan akan naik sebesar 13,08\% dengan asumsi bahwa variabel lain dianggap tetap. Meningkatnya tenaga kerja sektor industri sedang dan besar mengakibatkan tingkat kemiskinan turut meningkat, dikarenakan tenaga kerja yang terserap lebih banyak tenaga kerja yang terdidik dan memiliki keahlian. Sedangkan pada masyarakat miskin, mereka adalah tenaga kerja yang kurang terdidik dan dengan keahlian yang terbatas. Selain itu, penggunaan teknologi baru juga menyebabkan kurang terserapnya tenaga kerja pada industri sedang dan besar yang ada di Kabupaten Gresik.

Sedangkan variabel produk domestik regional bruto (PDRB) sektor industri berhubungan negatif dan signifikan terhadap variabel tingkat kemiskinan, dengan nilai koefisien produk domestic regional bruto (PDRB) 
sektor industri sebesar -0,169431 dan probabilitas sebesar 0,0009 (lebih kecil dari $\alpha=0,05)$. Artinya, apabila terjadi kenaikan produk domestik regional bruto (PDRB) sektor industri sebesar 1\% maka kemiskinan akan turun sebesar 3 ribu jiwa dengan asumsi bahwa variabel lain dianggap tetap.

\section{KESIMPULAN}

Variabel jumlah industri sedang dan besar, tenaga kerja industri sedang dan besar serta produk domestik regional bruto (PDRB) sektor industri memiliki pengaruh yang signifikan terhadap variabel kemiskinan dan dapat menjelaskan pengaruh variabel bebas (independen) terhadap variabel terikat (dependen) sebanyak $72 \%$, sedangkan sisanya dijelaskan oleh variabel lain yang tidak dijelaskan dalam model penelitian. Variabel jumlah industri sedang dan besar berpengaruh negatif dan tidak signifikan terhadap variabel tingkat kemiskinan. Variabel tenaga kerja industri sedang dan besar berpengaruh positif dan signifikan terhadap variabel timgkat kemiskinan. Variabel produk domestik regional bruto sektor industri berpengaruh negatif dan signifikan terhadap variabel kemiskinan.

\section{SARAN}

Upaya untuk menurunkan jumlah kemiskinan, peningkatan produk domestic regional bruto pada sektor industri sangat diperlukan dan hal ini berpengaruh terhadap menurunnya angka kemiskinan. Pada jumlah industri, sebaiknya diupayakan menciptakan industri yang padat karya daripada padat modal. Serta dilakukan pemerataan pembangunan sektor industri. Melakukan pemberdayaan terhadap tenaga kerja yang ada di Kabupaten Gresik yang bisa dilakukan dengan pelatihan tenaga kerja untuk meningkatkan softskill dari tenaga kerja tersebut. Untuk peneliti selanjutnya, diharapkan dapat melakukan penelitian dengan variabel yang berbeda untuk memperoleh hasil penelitian yang lebih luas lagi.

\section{DAFTAR PUSTAKA}

Arifin, Z. (2006). Konsentrasi Spasial Industri Manufaktur Berbasis Perikanan di Jawa Timur (Studi Kasus Industri Besar dan Sedang). Jurnal Humanity, Vol. 1(No. 2), 142-151. Press.

Arsyad, S. (2010). Konservasi Tanah Dan Air (Edisi Kedu). Bogor: IPB

Barirah, P. D. (2015). Analisis Pengaruh Pertumbuhan Ekonomi, Jumlah Tenaga Kerja, dan Inflasi terhadap Kemikinan di Kota Surakarta tahun 19952013.

BPS, kab gresik. (2016). BPS Kabupaten Gresik. Retrieved from https://gresikkab.bps.go.id

Heriansyah, R. D., Nuraini, I., \& Kusuma, H. (2018). Analisis Pengaruh Jumlah Industri dan Indeks Pembangunan Manusia terhadap Jumlah Penduduk Miskin di Kaabupaten/Kota Provinsi Banten tahun 2012-2016. Jurnal Ilmu Ekonomi, Vol. 2(No. 3), 453-463.

Mahsunah, D. (n.d.). Analisis Pengaruh Jumlah Penduduk, Pendidikan dan Pengangguran terhadap Kemiskinan Di Jawa Timur. 
Maipita, I. (2014). Mengukur Kemiskinan Dan Distribusi Pendapatan. yogyakarta: UPP STIM YKPN.

Murohman, Hutagaol, M. P., \& Asmara, A. (2014). Peranan Sektor Ekonomi dalam Pengentasan Kemiskinan di Kalimantan Barat. Jurnal Ekonomi Dan Kebijakan Pembangunan, Vol. 3(No. 1), 23-41.

Nuraini, I. (2013). Potensi dan Model Pengembangan Industri Manufaktur di Kota Malang. Jurnal Gamma, Vol. 9(No. 1), 155-169.

Sudarti. (2011). Model Pemberdayaan Masyarakat Miskin Berbasis Industri Kecil/Kerajinan (IKK). Jurnal Humanity, Vol. 7(No. 1), 64-72.

Suliswanto, M. S. W., Abdullah, M. F., \& Yuli, S. B. C. (2018). Mengurai Benang Kusut Kemiskinan.

Susanti, S. (2013). Pengaruh Produk Domestik Regional Bruto, Pengangguran dan Indeks Pembangunan Manusia terhadap Kemiskinan di Jawa Barat dengan Menggunakan Analisis Data Panel. Jurnal Matematika Integratif, Vol. 9(No. 1), 1-18.

Susilowati, D., \& Suliswanto, M. S. W. (2015). Pertumbuhan Ekonomi, Indeks Pembangunan Manusia, Utang Luar Negeri dan Kemiskinan (Kajian Teoritis di Indonesia). Jurnal Ekonomika-Bisnis, Vol. 6(No. 1), 89-106.

Tambunan, T. (2003). Perekonomian Indonesia. Jakarta: Ghalian Indonesia.

Tisniwati, B. (2012). Analisis Faktor-Faktor Yang Mempengaruhi Tingkat Kemiskinan di Indonesia. Jurnal Ekonomi Pembangunan, Vol. 10(No. 1), 33-46.

Todaro, \& Smith. (2006). Pembangunan Ekonomi (Edisi 9). Jakarta: Erlangga.

Wahyuningsih, Y. E., \& Zamzami. (2014). Analisis Pengaruh Produk Domestik Regional Bruto dan Jumlah Penduduk Terhadap Tingkat Kemiskinan di Kabupaten Nagan Raya. Jurnal Ekonomi Dan Kebijakan Publik Indonesia, Vol. 1(No. 1), 39-47. 